\title{
Studies on the Commercialization of Research Outcomes with a License at Jambi University \\ Dwi Suryahartati ${ }^{1 *}$, Windarto ${ }^{1}$
}

\author{
${ }^{I}$ Facuty of Law, Universitas Jambi, Indonesia \\ *Corresponding author. Email : dwisurya@unja.ac.id
}

\begin{abstract}
Higher education institutions are one of the centers of research activities throughout the world. The amount of research and research results that can be commercialized is not comparable. The policies for the independent campus and the independent learning have an influence on the research amount. Research outcomes must reach the community and technology transfer and are carried out through legal mechanisms. One of them is with a license. This paper describes the commercialization of research outcomes at Jambi university. The purpose of this paper is to look at the legal aspects of the commercialization of research outcomes and how the license accommodates the commercialization of them at Jambi university. The main obstacle was lack of understanding on: the commercialization process, the ability to see the potential for commercialization, and the legal aspects related to commercialization. Literature study and interview method were carried out for this research. The data gathered were quantitative and qualitative ones.
\end{abstract}

Keywords: Commercialization, License, Research.

\section{INTRODUCTION}

Higher Education as a research-producing institution is a necessity. Research results or outcomes must be a solution to all problems. They should be delivered to the commercialization stage. Currently, the Indonesian government has a policy called the Independent Campus (Kampus Merdeka) and Independent Learning (Merdeka Belajar) which has an impact on the delivering of research results. The policy of an independent campus and independent learning affects the results of research since research is carried out with the integration of its fields. It certainly has an impact on society. Research results from Higher Education institutions have approached the needs of the general public. Obviously, in order to be utilized, technology transfer is needed. The transfer of technology is carried out through a legal mechanism. There are many ways to commercialize research results, one of them is with a license. The license determines the rights and obligations deal with a technology, its development and technology transfer for an invention/innovation. A problem for research results in Indonesia is the stage of commercialization and application of the license.

The main assets for the progress of a nation are science and technology. Many countries in the world do not have large natural resources, but their level of willingness exceeds countries that are rich in natural resources. It turns out that with these scientists and technology, these developing and sustainable countries become advanced. Research is one indicator of progress in science and technology. Higher Education Institutions are one of the centers of research activities throughout the world. Research results must be able to be utilized and commercialized. In principle, a research aims at producing benefit and usefulness for science and technology. Ministry of Higher Education Research in 2019, through data from SINTA there were 177,000 lecturers and researchers who uploaded their research results. In addition, there are 18,000 books, 2,600 journals, and 5,000 intellectual property rights registered with SINTA. The Minister of Research and Technology and the Head of the National Research and Innovation Agency said that the rough calculation of research funds for 2020 is worth IDR 30 trillion.

Research results that are produced - whether funds allocated by the government or other parties - are science that needs to be protected by law, namely the law of intellectual property. The new paradigm in research is that research must be oriented towards invention and innovation, and it is hoped that these inventions and innovations will reach the community as users or consumers, both mediators and final consumers. Inventions and innovations in Higher 
Education institutions need to be managed with a good system. In this case, if they want to be economically beneficial, precisely, it should be processed through business mechanisms.

Research results do not only stop in the archive room and end with a patent registration. Furthermore, the success of a research project is determined by its usefulness. However, the commercialization process requires a scheme that stakeholders must understand synergistically. The results of research that have been granted patents are generally not immediately applicable since they require a process of preparing technology, manufacturing product samples, field studies, and business planning. Indeed, not all research results can be commercialized due to the various categories of research itself.

The commercialization of research results is an important factor so that research is truly enjoyed by the community, not just as state documentation. To start a business without taking into account the protection of Intellectual Property Rights (IPR) is a mistake. It is a wrong step if the process of an IPR application is done after a dispute or after seeing the benefits and suspicions of the sustainability of the ideas and works. It can make the work of entrepreneurs easily stolen. Since the early days of starting the business, the protection of the IPR should have been provided. IPR can actually be a valuable asset that can save a company in difficult times. IPR is very important in the business since it shows its advantages and responsible competitiveness. Even IPR can be the basis for profitable innovations.

In Indonesia, the delivering of research products and science and technology products has many obstacles. Higher education institution is demanded to create science and technology since there are many potential experts. However, the results of the research revealed that very few technologies developed by Limited Company or Joint-stock Company (Perseroan Terbatas) were used commercially. From the results of their research at several universities in America, Mark and Mainelll revealed that out of 100 research ideas in universities, only 10 continued on a research project. Of the ten projects, only two had commercial potential and of these two projects only one was truly profitable. It turns out that ITB as a technology-based university has produced many patents, meanwhile their commercialization is not comparable. For example, Jambi University is a public university in Indonesia. The data shows that in 2019 there were 694 research titles and only 100 studies had commercial potential. after that, 30 titles were selected again to be submitted again. There are 21 titles that meet the criteria and are deemed worthy of being commercialized. Of the 21 titles, only 3 studies met the prerequisites with level 9 Technology Readiness Level (TRL). Meanwhile, there were 5 products. science and technology that has been marketed and commercialized from 2015 to 2018.

For commercialization, there are several ways that can be taken to transfer the technology with legal mechanisms. Legal mechanisms are aligned with business needs in the form of Sale or Assignment; Licensing; Joint Venture Agreement; Franchising; Distribution networking. In this study, researchers focused on the licensing mechanism. Licenses in the Intellectual Property system are called compulsory licenses and voluntary licenses. Licensing in this context is associated with the commercialization of research results in Higher Education. License is the granting of a permit for the use of a product or service. A license is an agreement between the licensor and the licensee. The licensor and the licensee create a deal relating to the production, development, manufacture, marketing and other benefits of goods or services for an intellectual work. Regarding the legal basis for licensing of intellectual property, there are already various laws in the field of intellectual property. One of them is Law Number 13 of 2016 concerning Patents (Patent constitutionsUUP). According to Article 1 number (11) UUP a license is an authority granted by a patent holder, either exclusive or non-exclusive, to the licensee based on a written agreement to use a patent that is still protected within a certain period of time and with certain conditions. At Jambi University, based on data from the papers center, patent applications and patents that have been granted are not proportional to the amount of research. Likewise, the delivering and commercialization processes have not been significantly implemented.

Since the era of the old order, the government has always said that universities must approach the industry. Even now it is still stated that way. Is this a sign that these conditions have not been achieved? All policies that lead to the use of intellect in Higher Education are protected in the Intellectual Property Law Regime.

The research method is very influential on the truth. According to Cornelius Benuf, if there is an error in choosing the research method, it will cause new legal problems [1]. This research was qualitative with the type of document study with phenomenological considerations. It applied a theoretical basis as a guide and started from the field data using existing theories as support, then generated a theory from the data. This research was qualitative with a phenomenological approach. This research method used empirical facts from human behavior verbally and interviews as well as actions in reality in the field or documents and archives [2]. The research was conducted in 2020 at Jambi University with central data from the Institute for Research and Community Service / LPPM. The research subjects were researchers as well as participants. Sampling was carried out by a purposive sampling technique, namely selecting samples that were tailored to 
the needs of the study. Respondents consisted of researchers whose research had an impact on commercialization with informants from the Head of LPPM, Head of Business Incubators, officials related to the research. Documents and research results for the last five years from 2015 to 2019 were also included. The data were also collected by reviewing and analyzing literature and documents related to the object of research, then making statements. Data analysis was carried out by describing all information, reducing and sorting it according to need. Then the results were presented descriptively and analytically. The data were then analyzed by interpreting the descriptive analytical method, which is not merely explaining, but also describing and analyzing the content and structure of the applicable positive law [3].

\subsection{Legal Aspects of Commercialization}

Research results must be legally protected. According to John Kirkland, research activities in each country are different. Even in developed countries, the systems and procedures can be developed in no less than 20 years. So far, the process is still incomplete [4].

To obtain economic value from research and invention, legal rights are required. Intellectual property can give rise to a right because of human thought, initiative and work to present tangible work. This work can be enjoyed by humans for both processes or a product. The core of intellectual property rights is the right to enjoy material rights which produce material and immaterial rights. Scientific work is divided into two parts, namely copy rights and industrial assets. The copyright protects works in the fields of art, literature, and science. Industrial Property protects industrial designs, integrated circuit layout designs, branding and geographic indications, trade secret patents, and Property Rights in the Industrial Sector, covering protection of Patents, Trademarks, Industrial Designs, Trade Secrets and Integrated circuit layout designs.

In Law Number 28 of 2014 concerning Copyright, intellectual property in the form of arts, literature and science is given legal rights to be protected under this law. Findings in the field of technology in the form of products, processes or product development and product improvements have a patent law and are legally protected. In law number 20 of 2016 concerning trademarks and geographic indications, logos or symbols or identities in the form of images, writings or combinations are protected by this law. In contrast to two-dimensional or three-dimensional forms, legal rights are granted by Act No. 31 of 200 concerning industrial design. Intellectual property in the form of business / technology information that has economic value is granted legal rights in the form of Law Number 30 of
2000 concerning Trade Secrets. For plant varieties protected by Law Number 29 of 2000. For Layout Designs of Integrated Circuits protected by Law Number 32 of 2000.

In Indonesia, IP does not have the support and increases income and royalties, due to different paradigms in research in universities and in an industry. IP system is relatively good, but its management is less useful for researchers. In higher education, it is necessary to have policies that are oriented towards the management of research results. If the regulations on IP for higher education can be said to be below standard, then it is impossible for researchers to have economic rights according to their initiatives and work. Unfortunately, researchers do not get an honorium for their research activities, in the legislation there are research activities, even though the output paradigm prevents researchers from being creative. At present, many universities are independently collaborating in order to encourage researchers to conduct research and innovation, but the provisions in the IP system are not in line with research activities in tertiary institutions. for example, Patents and Liability for maintenance costs.

The aim of the research is to develop knowledge absolutely and be beneficial to society. IPR functions to optimize economic and moral rights. In commercialization, a technology has moved from an agricultural activity to a production and consumption that generates profits for all people, be it inventors, universities, society and even competitors. in higher education, superior research results are used as a potential to enter the commercial market. Therefore, the research road map at the university should be focused. Of course, the desired research result is research carried out in an integrated manner, or linked through multidisciplinary knowledge, then supported by a good environment and responsive policies.

It does take time to establish a good environment and research system that is leading to commercialization. However, by looking at the existing regulations, the direction has shown the goal of commercialization. It is called a patent. The inventors are very excited to research and continue to register the patent rights. By doing so, it should be continued at the delivering and commercialization stages by calculating the valuation value. It is also in line with what Eddi Herjanto has researched and the results show that the respondents have already known about patents although the protection and criteria for the invention are not well understood. Respondents have not mastered patent and public domain information. Hence, it still requires technical guidance on patents. Almost all respondents believe that the use of patent information requires government support, especially in the form of organizing patent search training [5]. 


\subsubsection{Form of Commercialization}

In principle, intellectual property rights are a means to achieve exclusive benefits and economic value. Economic value is obtained when the invention is able to be used to meet the needs of society in general. Fulfillment of these needs starts from new ideas, containing inventive steps and can be applied in the field of technology. Obviously, the invention can be applied in the industrial world. In the Indonesian Patent Law, inventions can be in the form of products or processes or product development, and the patent has never been disclosed before. To commercialize the research results that produce a "royalty". There are many ways are: License, Franchise, Joint Venture, Foreign investment business, Joint Operation

\section{LICENSE AS A WAY TO PROTECT AND USE THE ECONOMIC RIGHTS OF INTELLECTUAL PROPERTY}

If you want to enter the world of industry, the use of research results will be in the first spotlight. In the 1980s, the Bayh-Dole Act caused a paradigm shift among US academics. the amendments took the form of patents resulting from a federal research grant. this led US universities to adopt a policy of increasing the number of patent applications [6]. In addition, to support the implementation of the commercialization of a policy is needed. policy makers must be able to create a synergistic integrated policy in accordance with their duties and functions. as for the policies made must be mutually beneficial for the parties who sign the agreement.

\section{RESEARCH RESULTS MAP OF JAMBI UNIVERSITY}

Research at Jambi University was conducted by referring to the Jambi University Strategic Plan. This study describes the strategic plan from 2015 to 2020 in accordance with the related the year of strategic plan. Referring to the Strategic Plan of the Ministry of Research, Technology and Higher Education 2015-2019, the Jambi University Strategic Plan 2015-2019 is focused on 7 (seven) Strategic Targets. Among the 7 targets, one of which is to increase the quality and quantity of research and community service. Related to the vision of Jambi University, namely: "A World Class Entrepreneurship University", the clarity of the World Class A world class vision means Jambi University is one of the world's reputable universities, with reputation indicators, one of which is international reputation in research. The vision for research is supported by the mission of carrying out various creative and innovative researches that support the implementation of quality entrepreneurial education, both at the national and international levels.
Besides having a strategic plan, Jambi University has a business plan which contains a research pattern that is adjusted to the vision and mission. Jambi University's efforts to improve research performance have been carried out through various activities, including: conducting research proposal writing training, developing study centers, evaluating and monitoring research implementation, conducting training in applying for patents/intellectual property rights, disseminating research results, conducting article writing training for accredited journals. From these efforts, it seems that there has been no visible effort to commercialize research results. Efforts are still limited to disseminating research results. It shows that there is no synergy between the vision and mission of Jambi University and the objectives of the research that has been modeled by the Ministry of Research and Technology.

Research at Jambi University is conducted through internal and external funding. The number of researches has increased relatively from year to year. Until 2016, the funds allocated for research were not less than 8 billion Rupiah. In 2019-2020 the research budget at Jambi University has increased to 27 billion Rupiah. It must be adjusted according to the output to be achieved. So far, the priority output is scientific publication. From the data obtained, the output for Intellectual Property and Commercialization is not significant and not even comparable. Centrally, research performance is very significant involving the role of lecturers as researchers. However, the data in the Jambi University Business Strategic Plan do not yet describe a plan to develop research results. Any single activity which describes the matter of commercialization has not been seen yet. By taking a look at the strategic plan of the Institute for Research and Community Service as an institution that supervises the training and service of lecturers at Jambi University, it will be seen that one of the priority strategic plans of the LPPM Jambi University is to increase the acquisition of Intellectual Property Rights.

Talking about commercialization, not all research has this potential. To be included in the potential commercialization, the research results should be able to be applied to a research project with TRL levels starting from level 7-9. According to informant A, that research at Jambi University is increasing every year, both in terms of budget and number of researches ${ }^{9}$. The scheme being drafted is adjusted to the scheme referred to by the Ministry of Research, Technology and Higher Education / National Agency for Research and Innovation. The research results that have the potential to be delivered have been mentored. There are about 31 research titles recorded. However, it has not yet reached the stage where the research results will be evaluated. It describes that this institution still considers IPR its goal. Meanwhile, IPR is not a goal but a tool to achieve the goal. The goals that are in line with the duties of Higher Education are to benefit society in general. This means that on a basis, 
commercialization has not received a good portion at Jambi University.

\section{FORM OF COMMERCIALIZATION OF RESEARCH RESULTS AT JAMBI UNIVERSITY}

IP management in tertiary institutions has synergistic support between the Ministry of Law and Human Rights. in Law No. 18 of 2002 about the National System for Research, Development and Application of Science and Technology, Law Number 12 of 2012 about Higher Education, Law No 13 of 2016 about Patents, Government Regulation Number 20 of 2005 about Transfer Technology and Results of Intellectual Property for Higher Education Research and Development Activities and Research and Development Institutions, Government Regulation Number 4 of 2014 concerning Implementation of Higher Education and Management of Higher Education, Presidential Regulation Number 13 of 2015 about Ministry of Research, Technology and Higher Education, Ministry of Regulations Research, Technology and Higher Education Number 15 of 2015 about the Organization and Work Procedure of the Ministry of Research, Technology and Higher Education. If the above laws and regulations are implemented it can create several conflicts. In terms of commercialization, there are problems in the industry, even though all these regulations aim to raise the ranking of universities in Indonesia to the international arena.

the research culture of higher education and industry is very different, this raises problems in the industrial world. on the research culture in higher education has the nature of educating, solving problems and providing services. As for the mission of the research will be adjusted to the vision and mission of the university which is generally basic and applied research. In its research activities, it is hoped that the transfer of technology will be able to support the mission of applied research. different from industrial research, where the research leads to the development of innovation and commercialization, and the speed of research. carrying out products is the mission of industrial research. Research activities in industry are expected to have a direct impact

To start a business without taking into account the protection of Intellectual Property Rights (IPR) is a mistake. It is a step that is not correct if the process of an IPR application is conducted after a dispute or after the profit has been seen and suspicions about the continuity of the ideas and works. This can make the work of entrepreneurs easily stolen. Since the early days of starting the business, the protection for their IPR should be provided since IPR can actually be a valuable asset that can save a company during difficult times. IPR is very important in the business world because it will show its advantages and responsible competitiveness. Even IPR can be the basis for profitable innovations.

universities must be able to create a management system and utilization of research results. Yuan-Chieh et al [7] said that in conducting research, many parties and staff will be involved in the process. historically, delegated to individual researchers, who assumed that the agency's role was limited to staff involvement and provided a basic framework ${ }^{9}$.

in Indonesia, there are obstacles in the delivery of research and science and technology products. This is evidenced by the low level of technological readiness which causes delays in the delivery of higher education research results to the industrial world. It is due to the requirement of innovation and manufacturing or manufacturing readiness. At the macro level, the World Economic Forum (WEF) identifies 5 (five) important factors for maintaining competitiveness, namely: (a) The conducive level of macroeconomic conditions; (b) the quality of public institutions in carrying out their functions as facilitators and service centers; and (c) technology development policies to facilitate the need for increased productivity. Meanwhile, at the micro level or operational level, there are 2 (two) factors that stand out, namely: (a) technical efficiency of the business; and (b) business competition climate. At the macro strategic level, synchronization and collaboration of integrated strategic policies between universities or Research \& Development institutions, the government and the business world are needed in order to build a strong triple helix collaboration. At this level, the parties involved must be able to make policies that are integrated in collaboration and synergy with their duties and functions. as for the policies made must be able to benefit the third party who signed the agreement. a serious effort is needed in aligning tertiary research with industrial research. based on survey results at 122 universities in Taiwan, only 63 products can be brought to the real market.

In intellectual property management, marketing policies have not been supportive, even though it is very important to encourage the discoveries that the university has. IP rights management is very important in order to direct the results of research aimed at efficiency. there are several benefits in managing IPR; first, in the form of a strategy and framework that can improve accreditation; Both are strategies to improve quality and competitiveness; third, to become a strategy to obtain IPRs quickly, simply and effectively; Fourth, it becomes a strategy for developing information or documentation related to research; Fifth, to become a strategy in providing promotional services and commercialization of higher education institutions and their development; sixth, it can be a strategy in increasing revenue yields and fundraising in tertiary institutions. 


\section{CONCLUSION}

The conclusion from the results of this study is that from 2015 to 2019 there were 2,309 researches from all branches of science. The output that can be delivered is only about $7.7 \%$. From the results of the process towards delivering, there is still no license to use. Hence, it can be said that the use of the technology transfer method with a license has not been carried out. This is due to a lack of understanding of the intellectual property-oriented research cycle and culture. The obstacle faced in leading to commercialization is that researchers generally do not understand how the flow of the research process to the stage called commercialization is the impact of the economic benefits of an intellectual property right. Another obstacle is that regulations related to the management of intellectual property are inadequate to accommodate commercialization. Institutions to support the implementation of commercialization have not been established. Therefore, it is advisable to always carry out socialization and workshops related to knowledge and skills in the field of intellectual property, to form institutions or institutions that support commercialization activities as a result of research to have an impact on society. Making regulations and legal instruments on asset management that have been drafted by researchers.

\section{SUGGESTIONS}

1. It is recommended for the government to make regulations that improve existing regulations regarding the use of research results in higher education institutions; hence, they have a quick impact on society.

2. Stakeholders at Jambi University are suggested to immediately create instruments and legal umbrella regarding the management of Intellectual Property at Jambi University and form an institution that has the task of managing the intellectual property of research results which can use the license draft produced by this study for the management of IP at Jambi University.

3. For researchers at Jambi University, it is expected to be able to follow the development of intellectual property science through socialization and workshops.

\section{AUTHORS' CONTRIBUTIONS}

Authors 1: contribute to primary and secondary data and analysis theory

Author 2: contribute to data processing and manuscripts

In general, this research produces research patterns at Jambi University and the classification of researches at Jambi University, so that you get the right commercialization model for research at Jambi University.

\section{ACKNOWLEDGMENTS}

Thank you to the rector of Jambi University for the grant provided for the conduct of this research and all related parties who have contributed to this research.

\section{REFERENCES}

[1] K. Benuf \& M. Azhar. 2020. Metode Penelitian Hukum Sebagai Instrumen Mengurai Permaslahan Hukum Konteporer, Jurnal Gema Keadilan, Volume 7 Edisi I, Juni 2020, Universitas Diponegoro, Hal. 21

[2] M. Fajar, \& Y. Achmad, 2010, Dualisme Penelitian Hukum Empiris \& Normatif, Pustaka Pelajar, hlm.280

[3] B. J. Nasution, 2008. Metode Penelitian Hukum. Mandar Maju, Bandung, hal. 91

[4] J. Kirkland. 2008. University research management: an emerging profession in the developing world, Technology Analysis \& Strategic Management Vol. 20, No. 6, November 2008, 717-726 University research management: an emerging profession in the developing world John Kirkland*Technology Analysis \& Strategic Management Vol. 20, No. 6, 717-726 , p. 718

[5] E. Herjanto. 2019. Pemahaman Dan Penerapan Paten Di Balai Litbang Industri Understanding And Application Of Patent In Industrial $R \& D$ Institutions, Jurnal Riset Industri, Vol. V, No. 1,

[6] A. D. Daniel \& L. Alves. 2019. Universityindustry technology transfer: the commercialization of university's patents, Knowledge Management Research \& Practice, https://doi.org/10.1080/14778238.2019.16387 $\underline{41}$, p. 1

[7] Y. C. Chang, M. H. Chen, M. Hua \& P. Y. Yang (2005) Industrializing Academic Knowledge In Taiwan, Research-Technology Management, 48:4, 45-50 To link to this article: http://dx.doi.org/10.1080/08956308.2005.116573 $\underline{24}$, p. 719 